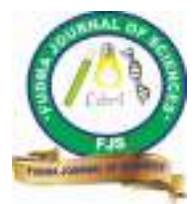

FUDMA Journal of Sciences (FJS)

ISSN online: $2616-1370$

ISSN print: 2645 - 2944

Vol. 4 No. 3, September, 2020, pp $645-655$

DOI: https://doi.org/10.33003/fjs-2020-0403-319

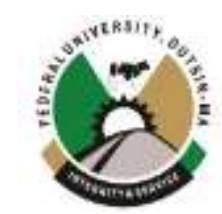

\title{
SEROPREVALENCE AND RISK FACTORS ASSOCIATED WITH HPV INFECTIONS AMONG PATIENTS IN KOGI
} EAST SENATORIAL ZONE

\author{
${ }^{1,2}$ Awulu, O. F., ${ }^{1}$ Aminu, M., ${ }^{1}$ Suleiman, A. B. and ${ }^{1,2}$ Makolo, D. \\ ${ }^{1}$ Department of Microbiology, Faculty of Life Sciences, Ahmadu Bello University, Zaria, Kaduna State, Nigeria \\ ${ }^{2}$ Department of Science Laboratory Technology, School of Applied Sciences, Kogi State Polytechnic, Lokoja, Kogi State, Nigeria \\ *Corresponding Author's Email: awuluofriday@yahoo.com
}

\begin{abstract}
Analysis of prevalence and risk factors for Human Papilloma Virus (HPV) is the basis for prophylactic strategies against HPV infections. This study was to determine the seroprevalence of human papillomavirus, sociodemographic and risk factors associated with acquiring the virus among the study population. A total of 195 samples were collected by simple random sampling technique from three major hospitals in the zone. Serum from blood samples was used for ELISA and analyzed for IgM. Overall prevalence of 3.08\% (6/195) was established for HPV infection. Patients with early sexual activity and those with multiple sexual partners were likely to be infected than their counterparts with 15.8\%: $3 / 19\left(\chi^{2}=16.4, \mathrm{df}=3, \mathrm{p}=0.001\right)$ and 50\%: $2 / 4(\chi$ $2=30.2, \mathrm{df}=1, \mathrm{p}=0.005)$ respectively. The infection was more among those who got married at age range of 26-30 years with prevalence of 5.4\%: $2 / 37\left(\chi^{2}=1.30, \mathrm{df}=5, \mathrm{p}=0.82\right)$. On the basis of sex, female were found to have higher prevalence of $3.6 \%: 6 / 167\left(\chi^{2}=1.04, \mathrm{df}=1, \mathrm{p}=0.6\right)$. Subjects with sexually transmitted disease (STD) had a higher prevalence of $8 \%: 2 / 25\left(\chi^{2}=2.45, \mathrm{df}=2, \mathrm{p}=0.32\right)$. The study shows that infection with HPV was strongly associated with age of sexual debut and number of sexual partners. It also reveals the occurrence of HPV infection in Kogi East, Nigeria. Hence, there is need for routine screening, public education and vaccination to prevent the spread of the virus which is a threat to public health.
\end{abstract}

Keywords: Virus, HPV, Prevalence, ELISA, Risk Factors, Immunoglobulin (Ig).

\section{INTRODUCTION}

Human Papilloma virus (HPV) is a double stranded (ds) DNA virus, about $55 \mathrm{~nm}$ in diameter with an approximately $8 \mathrm{~Kb}$ genome in a nucleohistone core. It belongs to the Papillomaviridae family that contains more than 130 genotypes (Frazer, 2010). The predominant types are those types causing anogenital, oral or laryngeal infections, they are the types 6, 11, 16 and 18 (Gibbs, 1998; Vanchiere, and Demmer, 2004). It can also affect the human skin and moist membranes that line the body, such as the throat, mouth, feet, fingers, nails, anus and cervix. Most known HPV types cause infection without symptoms to humans. However, some can cause verrucae (warts), while a small number can increase the risk of developing several cancers, such as that of the cervix, penis, vagina, anus and oropharynx (oral part of the pharynxthroat cancer) (Franco, et al., 2001; Gillison, et al., 2008; Watson, et al.,2009).

Studies have shown that long-term persistence infection with HPV is a necessity for the development of cervical cancers, and the majority of women with HPV infections show a "healthy" phenotype for most of their lifetime (Sycuro, et al., 2008; Lee, 2012).

The Center for Disease and Control (CDC) reported that over 90\% of new HPV infections including those with high-risk types, clear or become undetectable within two years, and clearance usually occurs in the first 6 months after infection (Molano, et al., 2003; Hariri, et al., 2014). However, in 5\% to $10 \%$ of cases, the infection persists and persistent long-term HPV infection raises the risk of developing pre-cancerous lesions of the cervix as well as invasive cervical cancer
(Hariri, et al., 2014).

Globally, it has been estimated that at least $50 \%$ of sexually active adults have had genital HPV infection and $75 \%$ of individuals (males and females) experience an HPV infection at least once in their lifetime (Touzé, et al., 2001; Aminu, et al., 2014). The highest rate of infection usually occurs in individuals under the age of 25years (Di Giuseppe, et al., 2008; Trim, et al.,2012). In a recent meta-analysis, the reported global HPV prevalence is $11.7 \%$, prevalence in North America and Europe was estimated to be $11.5 \%$ and $14.2 \%$, respectively, while the estimated prevalence for Africa was $21.1 \%$, with sub-Saharan Africa topping the list at $24 \%$ (Dahlstrom, et al., 2010; Ezenwa, et al., 2013). In Nigeria, about $23.7 \%$ of women and $73 \%$ of men of the general population harbor HPV genital infection (WHO/ICO., 2012). Prevalence of HPV is high in females of all age groups, but highest in females between the ages of 15-23years (Dahlstrom, et al., 2010; Ezenwa, et al., 2013; Bruni, et al., 2014). Therefore, the study was to determine the prevalence of HPV among patients in Kogi East using serum, also possible risk factors for infection in the study area with the aim of providing public awareness of the virus.

\section{MATERIALS AND METHODS}

Study Area: The study was carried out in the East Senatorial Zone of Kogi State using three zonal hospitals. The state lies between latitude $6^{\circ} 31^{\prime}$ and $8^{\circ} 00 \mathrm{~N}$ and longitude $6^{\circ} 30^{\prime}$ and $7^{\circ} 50^{\prime} \mathrm{E}$ South of river Benue and East of river Niger. The east Senatorial Zone comprised nine (9) Local Government Areas (LGA), namely; Ankpa, Bassa, Dekina, Ibaji, Idah, 
Igalamela/Odolu, Ofu, Olamaaboro and Omala. The people are mostly farmers, business men and women and civil servants. The major hospitals in the zone are the zonal hospitals which were used for the study. There are located in three LGAs (Ankpa, Dekina and Idah)(Figure 1).

\section{Study Population}

The study population comprised of male and female patients attending the general outpatient department (G.O.P.D) of selected hospitals.

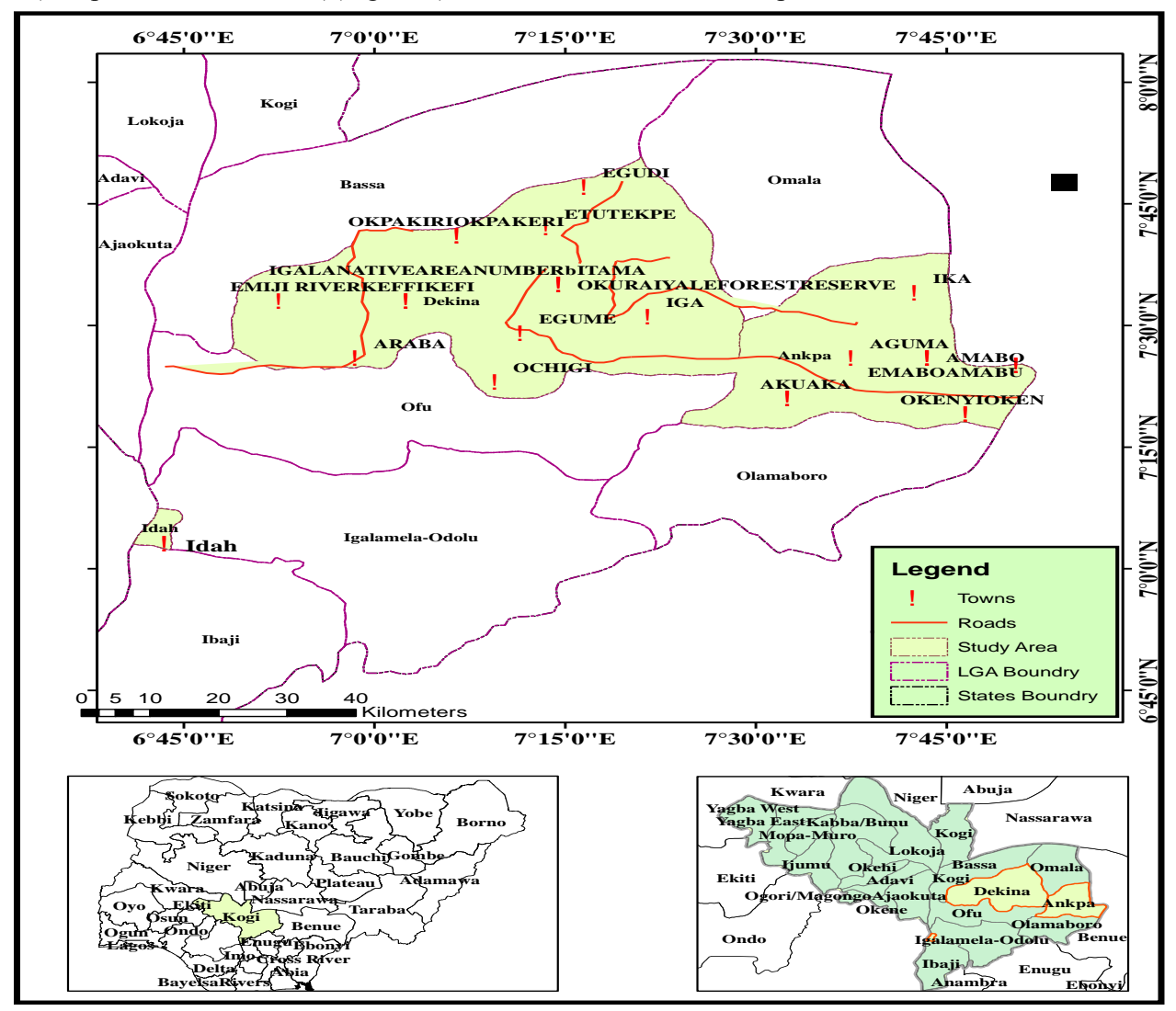

Figure 1. Map of Kogi East showing the Study Area (Kogi State Ministry of Land)

\section{Study Design}

The study was a cross sectional hospital based study, where blood samples were collected using simple random sampling technique from consented patients at the General Outpatient Department (G.O.P.D) of the selected hospitals in the three selected LGAs.

\section{Ethical Approval}

Ethical approval (Appendix I) was obtained from the State Ministry of Health and Ethics Committee in charge of the selected hospitals prior to the study.

\section{Data Collection using Questionnaire}

A structured questionnaire was administered to consented individuals. English and other local dialects were used where necessary to aid the in gathering of necessary information on socio-demographic, clinical presentation and some possible risk factors for HPV infection.

\section{Sample Collection and Processing}

The sample size was calculated using the formula by Sarmukaddam and Gerald (2006), Charan and Biswas (2013) as shown below and a prevalence of $14.7 \%$ as reported in a study conducted in rural Nigeria (Clarke, et al., 2011)

$$
\mathrm{n}=\frac{\mathrm{Z}^{2} \mathrm{pq}}{\mathrm{L}^{2}}
$$

Where: $\mathrm{n}=$ is the sample size

$\mathrm{Z}=$ is the standard normal distribution at $95 \%$ confidence interval $=1.96$

$\mathrm{p}=$ is the prevalence rate which is $14.7 \%$ (Clarke et al., 2011)

$$
1-\mathrm{p}=\mathrm{q}=1-0.147=0.853
$$

$\mathrm{L}=$ is the allowable error, which is taken as $5 \%=0.05$

Therefore, $\mathrm{n}=\left(\underline{1.96)^{2} \times 0.853 \times 0.147}=192.8=193.0\right.$

$$
(0.05)^{2}
$$


The calculated sample size was approximately 193 which is the least sample size for the study therefore, 195 blood and swab samples were collected and used for the study.

A total of 195 blood samples were collected from consented patients and processed as follows:

\section{Blood Samples}

Five milliliter $(5 \mathrm{mls})$ of whole blood was collected by a physician from men and women in the G.O.P.D sections of the selected hospitals by venipuncture into sterile plain bottles. The blood was centrifuged at 1,000 revolutions for 10 minutes to separate the serum. The serum for each sample was removed with a transfer pipette in order to avoid extraction of red blood cells along and was aseptically transferred into a sterile labeled serum storage screw cap container and stored in the freezer at $-20^{\circ} \mathrm{C}$ until required for analysis (ELISA).

\section{Analysis of Blood Samples}

The blood samples were analyzed for IgM using ELISA as outlined below:

\section{Human Papilloma virus Antibodies screening using ELISA}

The sera separated from the collected blood were analyzed using Enzyme-Linked Immunosorbent Assay (ELISA) (Wkea Med Supplies Corporation, Changchun, China) to check for presence of IgM antibodies for HPV. This was done according to the manufacturer's instructions.

\section{Assay Procedure}

All reagents and samples were brought to room temperature and mixed thoroughly before using. The numbering of the samples was done in sequence to correspond to the microtitre plates. About $50 \mu \mathrm{ml}$ of the positive and negative controls was added to the positive and negative wells respectively. This was followed by the addition of $40 \mu \mathrm{ml}$ of the sample diluents into the blank well and $10 \mu \mathrm{ml}$ of the test sample making about 50uml of the sample dilution which was dispensed into appropriate wells. The plates were gently mixed and incubated for 30 minutes at $37^{\circ} \mathrm{C}$. The plates were washed by addition of a washing buffer to each well and allowed to stand for 30 seconds and then drained by blotting with tissue cloth. This washing step was repeated five consecutive times after which about 50ul of Horseradish Peroxidase (HRP) conjugate was added to each well, with the exception of the blank wells, and incubated for 30 minutes at $37^{\circ} \mathrm{C}$. Excess liquid was discarded and a washing buffer was added to each well. The plates were allowed to stand for 30 seconds and were drained by blotting with tissue. About 50ul of a chromogenic substrate was added to each well and incubated for 15 minutes at $37^{\circ} \mathrm{C}$. The reaction was brought to a stop by addition of 50ul stop solution to each well. Absorbance of the resultant reaction was read at $450 \mathrm{~nm}$ using ELISA plate reading machine.

\section{Interpretation of Results}

The average value of negative wells plus 0.15 was given as the cut off value (as specified by the manufacturer). Any sample whose optical density was less than the calculated cut off value was interpreted as having a negative HPV result while samples with a higher optical density than the calculated cut off value was reported as having a positive HPV result.

\section{Data Analysis}

Data obtained from the questionnaires and results of the tests were analyzed for statistical association using Chi square at $95 \%$ confidence interval and 0.05 significant level. Statistical package for social sciences (SPSS) version 21 was used for the statistical analysis. Results were presented in tables, figures and charts.

\section{RESULTS}

\section{Risk Factors Analysis}

Data obtained from questionnaires were analyzed and results showed highest occurrence of the respondents to be between the ages of $26-30$ years $(36.9 \%: 72 / 195)$ while the least were above the age of 41years $(1.0 \% ; 2 / 195)$. It was also observed that all the respondents were at least married once in their life time with the married ones accounting for $99.5 \%$ of the population (194/195).

Looking at the educational status, 9.7\% (19/195) attained primary education or school certificate, $45.6 \%(80 / 195)$ had secondary education while $41.0 \%(80 / 195)$ had tertiary education with 3\% (7/195), having no formal education. Among the respondents, we had $40 \%$ (78/195) of them to be involved in business, 20\% (39/195) Civil Servants, 14.4\% $(28 / 195)$ were students, $6.7 \%(13 / 195)$ were applicant while $19 \%(37 / 195)$ occupation were having an occupation doing (Table 1). 
Table 1: Prevalence of HPV based on Socio-demographic

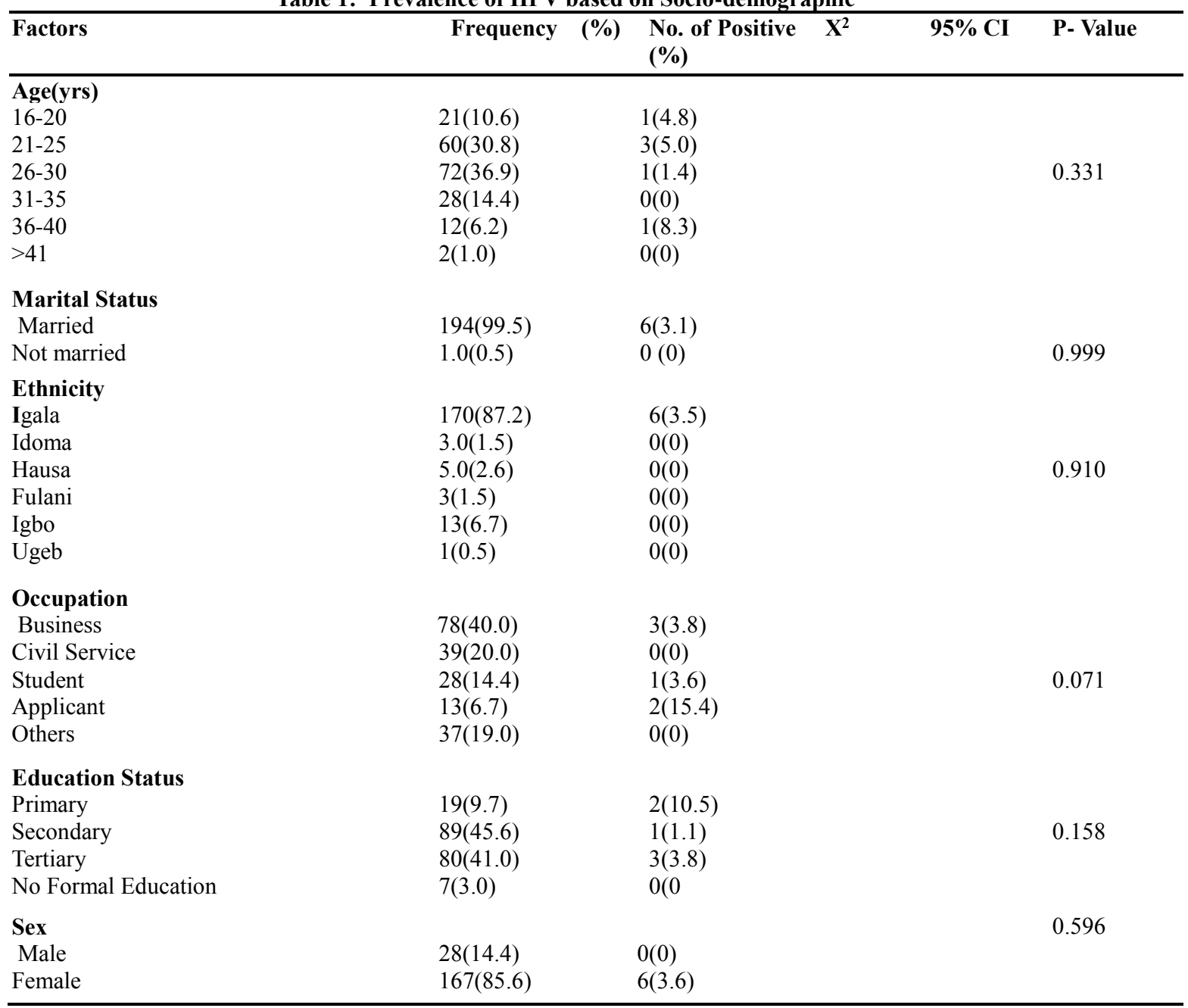

KEY; HPV=Human papillomavirus, Not married means either divorced, separated or widow

Sexual and reproductive behaviors of the people were considered important variables in the study because they play great role in the outcome of genital human papillomavirus infections. Analysis of these factors showed that $47.7 \%$ $(93 / 195)$ of the population are said to have being married between the ages of $16-20$ years which is the highest percentage occurrence and an active sexual age. This age group is followed by the age group $21-25$ years $(27.2 \%$ : $53 / 195)$ while $9.7 \%(19 / 195)$ of the patients showed to have being married at the ages less than or $16 y e a r s$.

The number of times an individual married (multiple marriage) is an important factor for HPV infections and development of lesions. In the analysis, 9.2\% (10/195) of the population have had multiple marriages while $90.8 \%$ $(177 / 195)$ had one marriage as at the time of study. The result from the respondents showed that 9.2\% (10/195) of the population had more than one sexual partner while $90.8 \%$ $(177 / 195)$ had one sexual partner. Those that have had one birth experience accounts for $21.5 \% \quad(42 / 195)$ of the population while those who have had more than one birth experience were $58.5 \%(114 / 195)$ and those without birth were 20\% (39/195) (Table 2).

Risk factors for HPV infections and lesions development are important in analyzing the prevalence study of HPV infection. In the analysis, it was seen that $2.1 \%(4 / 195)$ of the patients used at least one contraceptive type while 98\% (191/195) don't use any form of contraceptive. Of the total population, $13 \%(25 / 195)$ have had infection with STD, 3.1\% (6/195) have never had STD while $84.1 \%(164 / 195)$ don't have knowledge of their STD status. In the risk factors analysis, $10.3 \%(20 / 195)$ of the population use condom while $90 \%$ $(175 / 195)$ do not use condom during sexual intercourse. The data analysis showed $0.5 \%(1 / 195)$ of the people to have engaged in the use of sexual enhancer while $99.5 \%(194 / 195)$ do not use. Among the respondents, 1\% (2/195) smokes while $99 \%(193 / 195)$ do not smoke. (Table 3). 
Table 2: Prevalence of HPV base on reproductive characteristics

\begin{tabular}{|c|c|c|c|c|}
\hline Factors & Frequency (\%) & No. of Positive (\%) $\quad X^{2}$ & $95 \% \mathrm{CI}$ & P- Value \\
\hline \multicolumn{5}{|c|}{ Age at Marriage(yrs) } \\
\hline$\leq 16$ & $4(2.1)$ & $0(0)$ & & \\
\hline $16-20$ & $93(47.7)$ & $3(3.2)$ & & \\
\hline $21-25$ & $54(27.7)$ & $1(1.9)$ & & \\
\hline $26-30$ & $37(19.0)$ & $2(5.4)$ & & 0.820 \\
\hline $31-35$ & $5(2.6)$ & $0(0)$ & & \\
\hline$\geq 36$ & $21(0)$ & $0(0)$ & & \\
\hline \multicolumn{5}{|c|}{ No. of Marriage } \\
\hline 1 & $177(90.8)$ & $3(1.7)$ & & \\
\hline$>1$ & $18(9.2)$ & $3(16.7)$ & & 0.011 \\
\hline \multicolumn{5}{|l|}{ NSP } \\
\hline 1 & & & & \\
\hline \multirow[t]{2}{*}{$>1$} & $191(98.0)$ & $4(2.1)$ & & \\
\hline & $4(2.0)$ & $2(50)$ & & 0.005 \\
\hline \multicolumn{5}{|l|}{ No. of birth } \\
\hline 1 & $42(21.5)$ & $2(4.8)$ & & \\
\hline$>1$ & $114(58.5)$ & $2(1.8)$ & & 0.445 \\
\hline None & $39(20.0)$ & $2(5.1)$ & & \\
\hline \multicolumn{5}{|c|}{ Marriage type } \\
\hline Monogamy & $174(89.2)$ & $4(2.3)$ & & 0.127 \\
\hline Polygamy & $21(10.8)$ & $2(9.5)$ & & \\
\hline
\end{tabular}

Key: Yrs= years, $\mathrm{HPV}=$ Human papillomavirus, $\mathrm{NSP}=$ number of sexual partners

Table 3: Prevalence of HPV based on risk factors

\begin{tabular}{|c|c|c|c|c|}
\hline Factors & Frequency (\%) & $\begin{array}{l}\begin{array}{l}\text { No. of Positive } \mathrm{X}^{2} \\
(\%)\end{array} \\
\end{array}$ & $95 \% \mathrm{CI}$ & P-Value \\
\hline \multicolumn{5}{|l|}{ Age at FSC } \\
\hline$>16$ & $19(9.74)$ & $3(15.8)$ & & \multirow{4}{*}{0.001} \\
\hline $16-20$ & $115(59.0)$ & $0(0)$ & & \\
\hline $21-25$ & $53(27.2)$ & $2(3.8)$ & & \\
\hline$\geq 26$ & $8(4.10)$ & $1(12.5)$ & & \\
\hline Use & of & & & \\
\hline \multicolumn{5}{|l|}{ Contraceptive } \\
\hline Yes & $4(2.1)$ & $0(0)$ & & \multirow[b]{2}{*}{1.000} \\
\hline No & 191(98.0) & $6(3.1)$ & & \\
\hline \multicolumn{5}{|c|}{ History of STD } \\
\hline \multicolumn{5}{|c|}{ Yes } \\
\hline No & $25(13.0)$ & $2(8)$ & & \multirow{3}{*}{0.322} \\
\hline \multirow[t]{2}{*}{ Don't Know } & $6(3.1)$ & $0(0)$ & & \\
\hline & $164(84.1)$ & $4(2.4)$ & & \\
\hline \multicolumn{5}{|l|}{ Condom use } \\
\hline Yes & $20(10.3)$ & $0(0)$ & & \multirow[b]{2}{*}{1.000} \\
\hline No & $175(90.0)$ & $6(3.4)$ & & \\
\hline \multirow{2}{*}{\multicolumn{5}{|c|}{$\begin{array}{l}\text { Use of } \\
\text { Enhancer }\end{array}$}} \\
\hline & & & & \\
\hline Yes & $1(0.5)$ & $0(0)$ & & \multirow[t]{2}{*}{1.000} \\
\hline No & 194(99.5) & $6(3.1)$ & & \\
\hline \multicolumn{5}{|l|}{ Smoking } \\
\hline Yes & $2(1.0)$ & $0(0)$ & & \\
\hline No & 193(99.0) & $6(3.1)$ & & 1.000 \\
\hline
\end{tabular}

Key: $\mathrm{STD}=$ Sexually transmitted disease, $\mathrm{HPV}=$ Human papillomavirus 
Prevalence of HPV among the study population The seroprevalence of HPV based on sociodemographic was analyzed. Human papillomavirus IgM antibodies were found in serum samples of $3.08 \%(6 / 195)$ of the respondents. The highest prevalence of $4.6 \%$ was found among samples collected from Ankpa LGA while the lowest prevalence was found among samples collected from Idah LGA.

Respondents that were within the age group of $36-40$ had the highest prevalence of $8.3 \%$ and HPV was not detected among patients age group $31-35\left(\chi^{2}=3.70 \mathrm{df}=6, \mathrm{P}=0.33\right)$. The seroprevalence of HPV based on marital status showed a high prevalence of $3.1 \%$ among the married individual than that of those that are not married $0 \%$, an association which was not statistically significant $\left(\chi^{2}=, \mathrm{df}=1, \mathrm{P}=1.0\right)$. The seroprevalence of HPV was highest among the Igala ethnic group $(3.5 \%$ : $6 / 170$ ) while other ethnic group in the study showed no positives result to IgM antibodies.

The association was not statistically significant $\left(\chi^{2}=\mathrm{df}=5, \mathrm{p}\right.$ $=1)$. HPV infections was not significantly associated with respondents occupation $\left(\chi^{2}=9.20, \mathrm{df}=4, \mathrm{p}=0.07\right)$. IgM antibodies were found among those who were doing business, students and applicants with the highest among those doing business $(3.8 \%, 3.6 \%$ and $15.4 \% ; 3 / 78,1 / 28$ and $2 / 13)$. The seroprevalence of HPV according to the educational status was not significant $\left(\chi^{2}=5.02, \mathrm{df}=3, \mathrm{p}=0.16\right)$.

Antibodies positive to $\operatorname{IgM}$ were found among those with primary education, secondary education and tertiary education with prevalence values of $10.5 \%, 11 \%$ and $3.8 \%: 2 / 19,1 / 89$ and $3 / 80$ respectively. Based on the sex of the respondents, IgM antibodies to HPV were detected among the female with the seroprevalence of $3.6 \%(6 / 167)$ while the male had no antibodies. The association was not statistically significant $\left(\chi^{2}=1.04, \mathrm{df}=1, \mathrm{p}=0.60\right)$ (Table 1).

The sero-prevalence of HPV according to reproductive characteristics is shown in Table 2, shows highest prevalence of antibodies to HPV among participants who had been married between the ages of $26-30$ years $(5.4 \%$; $2 / 37)$ while the least occurrence of antibodies were found among those between the ages of $21-25$ years $(1.9 \% ; 1 / 54)$. The association was not statistically significant $\left(\chi^{2}=1.30, \mathrm{df}=5, \mathrm{p}\right.$ $=0.82$ ). Participants with multiple marriages were also observed to have highest prevalence of $\operatorname{IgM}$ antibodies to HPV $16.7 \%$, (3/18) while lowest prevalence of antibodies to HPV was found among those with single marriage $(1.7 \% ; 3 / 177)$. The association was not statistically significant $\left(\chi^{2}=12.3, \mathrm{df}=1, \mathrm{p}=0.01\right)$.

The prevalence of IgM antibodies was significantly associated with the number of sexual partners of the respondents $\left(\chi^{2}=\right.$ $30.2, \mathrm{df}=1, \mathrm{p}=0.005)$. Those with more than one sexual partner had the highest prevalence of antibodies to HPV which was found to be $50 \%(2 / 4)$ while those with single sexual partner had the least prevalence of $2.1 \%$ (4/191). Antibodies to HPV were also detected in the analysis of data according to number of birth. Those who had never given birth were found to have a higher prevalence of 5.1\% (2/39) while those with more than one birth had the lowest prevalence of $18 \%(2 / 114)$, there was no significant $\operatorname{association}\left(\chi^{2}=1.62, \mathrm{df}=2, \mathrm{p}=0.45\right)$.

\section{DISCUSSION}

The overall sero-prevalence of HPV in this study was found to be $3.08 \%$ which suggests that HPV is not endemic in the study area. This prevalence is similar to $3.29 \%$ prevalence reported in Sudan, (Salih, et al., 2010) but lower than the reported prevalence of $14.7 \%$ in rural Nigeria, $26.3 \%$ in Ibadan, Nigeria, $42.9 \%$ in Zaria and $40 \%$ in Southern Mozambique. (Menéndez, et al., 2010; Okolo, et al., 2010; Aminu, et al., 2014), 33.2\% in Benin Republic, 66.7\% in South Africa, 24\% in Sub-Sahara Africa, Eastern Africa, $21.4 \%$ in Eastern Europe, $16.1 \%$ in Latin America and the Caribbean. (Zizipho, et al., 2012).

The low prevalence in the present study compared with previous recorded prevalence may be due to a difference in the study population, differences in the age distribution of the participants, level of literacy, place of residence as well as sexual and reproductive characteristics. The low prevalence could also be due to the patients' life style and that of the population of the area. For instance high record of early marriage, smoking, multiple sex-partners and also multiple marriages were not seen in the study areas. The selected hospitals were referral centers where patients from this senatorial zone can be found in large number. The percentage so found therefore represents the actual sero-prevalence of HPV in the area.

In the risk factor analysis, infection with HPV has been shown to be related to the various risk factors (Ma, et al., 2013; Wiredu, and Armah, 2006; Aminu, et al., 2014). The age distribution pattern as observed in this study shows peak prevalence of HPV in the age group 36-40 years. This is a typical distribution pattern for infection with HPV described for population with high incidence of cervical cancer. (Auwal, et al., 2013; Wiredu and Armah, 2006; Thomas, et al., 2004). This is due to the sexual mode of transmission of the virus which allows re-infection and persistence of the virus for years may lead to cancer. It is also due to immunosenescence, infection with oncogenic types and more exposure to risk factors (Sellors, et al., 2003; Helen, et al., 2008; Aminu, et al., 2014). The detection of HPV in this population agrees with previous reports (Naucler, et al., 2007; Wiredu, and Armah, 2006; Aminu, et al., 2014).

The younger age groups were found positive for antibodies to HPV. This could be due to an early acquisition of the viral infection as a result of early indulgence in sexual activity, marriage and early sexual debut and acquisition of infection in the years after. The ages of 9-10 years have being reported to be age of sexual debut in Nigeria (Aminu, et al., 2014). The detection does not in any way signify the development of cancer because HPV infection in younger age population is transient and asymptomatic and also incidence of cancer in young age is very low and resolves with 1-2 years and may not have been found at time of study therefore the low prevalence. (Wiredu, and Armah, 2006; Aminu, et al., 2014).

The seroprevalence of antibodies to HPV according to marital status of the patients was not significant, however the prevalence was higher among the married patients and this is similar to a higher prevalence among married women (Aminu, et al., 2014). Yet other studies have reported higher 
prevalence among single women (Schlecht, et al., 2001; Sellors, et al., 2003; Tabora, et al., 2005; Menéndez, et al., 2010). The reason for this finding could be because the people especially the women in the study area often marry at young age of about $15 y$ years and it has been reported that early sexual debut and marriage are common risks factors for HPV infection and also acquisition of infection and re-infection years after marriage. The sero-prevalence of antibodies to HPV based on the occupation was not statistically significant in this study. This means, regardless of occupation, each patient in the study is at equal risk of being infected with HPV.

The socioeconomic factors identified in this study were similar to those identified for cervical cancer and other cancer in Nigeria (Thomas, et al., 2004; Adewuyi, et al., 2008; Wiredu, and Armah, 2006; Aminu, et al., 2014). The seroprevalence according to educational level shows higher prevalence among uneducated patients. This result is consistent with previous reports (Schlecht, et al., 2001; Naucler, et al., 2007; Thomas, et al., 2008; Wiredu, and Armah, 2006), however, Aminu, et al., (2014) reported a contrary prevalence. The observation in this study may be due to awareness campaigns on viral and sexually transmitted diseases in schools. Also in this study, the sero-prevalence of antibodies to HPV according to sex of the participants was not statistically significant, however a higher prevalence was observed among the female patients; a result which agrees with many previously reported prevalence (Serwadda, et al., 199; Gravitt, et al., 2002). This may be because women were more among the studied population and also may have decreased ability of clearing the viral infection or nutritional deficiencies. (Thomas, et al., 2004)

Other factors which are important risk factors and are similar to the identified factors were being considered as well (Thomas, et al., 2004; Adewuyi, et al., 2008; Wiredu, and Armah, 2006). The age at marriage of the patients was not significant. This means that, the acquisition of HPV could be at any time during marriage; a report similar to that reported by Aminu, et al., (2014). Also number of time a patient married had no statistical significant effect on the infection of HPV in this study. The sero-prevalence of antibodies to HPV in relation to the number of marriage was higher among those who had more than one marriage compared to those with single marital status in life. This could be as a result of an increased rate of sexual activity which could lead to high rate of HPV infection and also re-infection.

A statistical significant association was observed in the analysis of sero-prevalence of antibodies to HPV in respect to number of sexual partner. The sero-prevalence was higher in those who had more than one sexual partner than those with one sexual partner. This report is similar to early studies (Thomas, et al., 2004; Serwadda, et al., 1999; Wiredu, and Armah, 2006; Ma, et al., 2013; Aminu, et al., 2014). This is because rate of HPV infection always increases with increased number of sexual partners. Parity was also observed to have no significant effect on HPV infection in the study. In the present study, patients with high parity had the highest prevalence, a report that is consistent with previous reports (Okolo, et al., 2010 Helen, et al., 2008; Ma, et al., 2013) but contrary to other reports (Schlecht, et al., 2001; Wiredu, and
Armah, 2006; Aminu, et al., 2014). This result could be due to an increased sexual activity. Involving in early sexual activity has been identified as a most risk factor in the development of infection with HPV.

There was no significant sero-prevalence of antibodies to HPV infection in this study in the analysis of sero-prevalence of HPV infection according to the participants' type of marriage. This result contrasts the report of Aminu, et al., 2014 which reported similar prevalence for both polygamy and monogamy. The sero-prevalence of HPV antibodies was higher for polygamous marriage than monogamous in this study. This corresponds to the widely belief that sexual activity in persons with multiple sexual partners increases the risk of HPV infections. (Wiredu and Armah, 2006; Ma, et al., 2013; Aminu, et al., 2014). The sero-prevalence of antibodies to HPV in this study was not significant.

Age of sexual debut was found to be significantly associated with the presence of HPV. This is because, they acquired the virus at early age and antibodies clear after some time. Patients in this study who had their sexual debut at younger age had the highest prevalence of HPV antibodies. This agrees with previous reports of an increased HPV among people who indulge in sexual activity at an early age (Naucler, et al., 2007; Okolo, et al., 2010; Wiredu and Armah, 2006; Aminu, et al., 2014).

The use of contraceptive has been linked to infection with HPV (Thomas, et al., 2004). There was no significant association however, in this study; it was observed that those who do not use contraceptive had the higher prevalence. The reason could be because, the non-user of contraceptive are more exposed to high risk of infection with HPV. This result is similar to other studies that recorded a higher prevalence of HPV infection in women who do not use any form of contraception (Naucler, et al., 2007; Aminu, et al., 2014), however, the observation is different from previous reports (Schlecht, et al., 2001; Sellors, et al., 2003; Wiredu, and Armah, 2006).

In the analysis of history of (STD), no significant association was found in this study, a report different from previous report of association of HIV with HPV (Winkelstein, et al., 1984; Mbulawa, et al., 2018). Infection with sexually transmitted diseases exposes an individual to a higher rate of HPV infection. A higher prevalence was also observed among those who don't use condom as a means of protection during intercourse. Condom usage often prevents infection with sexually transmitted diseases which predisposes an individual to a higher rate of HPV infection. However, in this study, there was no significant association between condom use and HPV infection. Also there was no significant association between the use of sexual enhancer and infection with HPV. Another major risk factor for infection with HPV is smoking, however in this study HPV was not statistically significant and was detected with high sero-prevalence among nonsmoker. This could be due to the low fraction of smokers in the studied population. The result in this study is similar to that reported in Zaria, Nigeria by Aminu, et al., (2014) and contrasts the report of Schlecht, et al., (2001). An earlier report had it that cigarette smoking had a toxic effect and contributed to the development of low-grade squamous 
intraepithelial lesions and play a major role in invasive cervical cancer (Winkelstein, et al., 1984; Matsumoto, et al., 2003; Moscick, et al., 2006; Simen-Kapeu, et al., 2008) and also may induce and impaired antibody response in people infected with HPV.

\section{CONCLUSION}

The study found a prevalence of HPV IgM antibodies to be $3.08 \%$ indicating that the patients were infected with the virus and the virus is circulating with low prevalence in the state. Patients with low level of literacy, early sexual debut and multiple sexual partners were at higher risk of infection with HPV.

\section{Conflict of Interests}

Authors declare no conflict of interest.

\section{REFERENCES}

Adewuyi, S. A., Shittu, S. O. and Rafindadi, A. H. (2008): Socio-Demographic and Clinicopathologic Characterization of Cervical Cancers in Northern Nigeria. European Journal of Gynaecology. 29(1):61-61.

Aminu, M., Gwafan, J. Z., Inabo , H.I., Oguntayo, A. O., Ella, E.E and Koledade , A. K. (2014). Seroprevalence of human papillomavirus immunoglobulin $\mathrm{G}$ antibodies among women presenting at the reproductive health clinic of a University Teaching Hospital in Nigeria. International Journal of Women's Health, 6: 479-489.

Auwal, I.K., Aminu, M., Atanda, A.T., Tukur, J. and Sarkinfada, F. (2013). Prevalence and Risk factors of High Risk Human Papillomavirus Infections among Women attending Gynaecology Clinics in Kano, Northern Nigreia. Bayero Journal of Pure and Applied Sciences, 6(1): 67-71.

Bruni, L. Barrionuevo-Rosas, L. and Serrano B. (2014). Human Papillomavirus and Related Diseases in Nigeria. ICO Information Centre on HPV and Cancer (ICO, HPV Information Centre).

Charan, J. and Biswas, T. (2013). How to Calculate Sample Size for different Study Designs in Medical Research. Indian Journal of Psychological Medicine, 35 (2):121-126.

Clarke, Ma, Gage, J. C., Ajenifuja, K.O., Wentzensen, N.A., Adepiti, A.C., Wacholder, S., Burk, R.D. and Schiffman, M. (2011). A Population-Based, Cross-Sectional Study Of Age Specific Risk Factors for High Risk Human Papillomavirus Prevalence in Rural Nigeria. Infectious Agent of Cancer, 6:12.

Dahlstrom, L.A., Tran, T.N., Lundholm, C., Young, C., Sundström, K. and Sparén, P., (2010). Attitudes to HPV vaccination among parents of children aged 12-15 years - a population-based survey in Sweden. International Journal of Cancer, 126: 500-507.

Di Giuseppe, G., Abbate, R., Liguori, G., Albano, L. and Angelillo, I.F. (2008). Human papillomavirus and vaccination: knowledge, attitudes, and behavioural intention in adolescents and young women in Italy. Britsish Journal of Cancer. 99(2):225-9.
Ezenwa, B.N., Balogun, M.R. and Okafor, I.P. (2013). Mothers' Human Papilloma Virus Knowledge and Willingness to Vaccinate their Adolescent Daughters in Lagos, Nigeria. International Journal of Women Health, 5: 371-377.

Franco, E.L., Duarte-Franco, E., Ferenczy, A. (2001). Cervical Cancer Epidemiology, Prevention and the Role of Human Papillomavirus Infection. Cancer Medical Association Journal, 164: 1017-1025.

Frazer, I. H. (2010). Measuring Serum Antibody to Human Papillomavirus following Infection or Vaccination. Gynecological Oncololgy, 118(1): 8-11.

Gibbs, N.F. (1998). Anogenital Papillomavirus Infections in Children. Curricullar Opinion Pediatry, 10: 393- 397

Gillison M.L., Disouza G., Wstra W., Sugar E., Xiao W. (2008). Distinct Risk factors profiles from Type 16 Negative Head and Neck Cancer. Journal of National Cancer institute, 100: 407-420.

Gravitt, P., Peyton, C. and Alessi, T. (2002). Improved Amplification of Genital Human Papillomaviruses. Journal of Clinical Microbiology, 38: 357-61

Hariri, S., Dunne, E., Mona, S., Unger, E. and Markowitz, L. (2014). Manual for the Surveillance of Vaccine-Preventable Diseases Human Papillomavirus. 5th Edition, 5-7.

Helen, Trottier, Salaheddin, Mahmud, José Carlos M Prado, Joao S Sobrinho, Maria C Costa, Thomas E Rohan, Luisa L Villa, Eduardo L Franco (2008). Type)-Specific duration of human papillomavirus infection: implications for human papillomavirus screening and vaccination. The Journal of Infectious Diseases. 197:1436-1447.

Lee, C.A. (2012). Human Papillomavirus (HPV) and Cervical Cancer. Journal of Insurance Medicne, 43: 178-181.

Ma, G.X., Wang, M.Q., Ma, X.S., Shive, S.E., Tan, Y. and Toubbeh, J.I. (2013). Pathways of Cervical Cancer Screening among Chinese Women. International Journal of Womens Health, 5: 351-359.

Matsumoto, K., Yasugi, T., Oki, A., Hoshiai, H., Taketani, Y., Kawana, T. and Yoshikawa, H. (2003). Are Smoking and Chlamydial Infection Risk Factors for CIN? Different Results after Adjustment for HPX DNA and Antibodies. British Journal of Cancer, 89(5): 831-3

Mbulawa, Z. Z. A., Shalkioyk, C., Hu, N. C., Mairing, T. I., Barnabas, S., Dabee, S., Jaspan, H., Kriek, J. M., Jaumdally, S. Z., Mullar, E., Bekker, L. G, lewiz, D.A, Dietrich, j., Gray, G., Passmore, J. S. and Willianson, A. L. (2018). Human Papillomavirus (HPV) Prevalence in South African Adolescents and Young Woman encourages expanded HPV Vaccination Campaigns. PLos, ONE, 13(1): eo190166.

Menéndez, C., Castellsagué, X., Renom, M., Sacarlal, J., Quintó, L., Lloveras, B., Klaustermeier J, Kornegay, J. R., Sigauque, B., Bosch, F. X, and Alonso, P.L. (2010). 
Prevalence and Risk Factors of Sexually Transmitted Infections and Cervical Neoplasia in Women from a Rural Area of Southern Mozambique. Infectious Diseases in Obstetrics and Gynecology.

Molano, M., Van den B.A. and Plummer M. (2003). Determinants of Clearance of Human Papillomavirus Infections in Colombian Women with Normal Cytology: a Population-based, 5-year follow-up study. American Journal of Epidemiology, 158: 486-494.

Moscick, A. B., Schiffman, M. and Kjaer, S. (2006). Updating the Natural History of HPV and Anogeintal Cancer. Vaccine, 24(3): 42-51.

Naucler, P., Ryd, W., Törnberg, S., Strand, A., Wadell, G., Elfgren, K., Rådberg, T., Strander, B., Johansson, B., Forslund, O., Hansson, B. G., Rylander, E. and Dillner, J. (2007). Human papillomavirus and Papanicolaou Tests to Screen for Cervical Cancer. New England Journal of Medicine.357(16):1589-97.

Okolo, C., Franceschi, S., Adewole, I., Thomas, J.O., Follen, M., Snijders, P.J., Meijer, C.J. and Clifford, G.M. (2010). Human Papillomavirus Infection In Women with and Without Cervical Cancer In Ibadan, Nigeria. Infectious Agent of Cancer, 5(1): 24.

Salih, M. M., Safi, M. E., Hart, K., Tobi, K. and Adam, I. (2010). Genotypes of Human Papilloma Virus in Sudanese Women with Cervical Pathology. Infectious Agents and Cancer. 5(26): 1750-9378-5-26.

Sarmukaddam, S. B. and Gerald, S. G. (2006). On Validity of Assumption while determining Sample Size. Indian Journal of commodity medium, 29(2): 2004-2006

Schlecht , N. F., Kulaga, S., Robitaille, J., Ferreira,

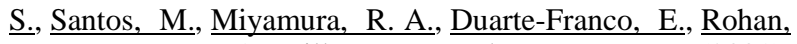
T. E., Ferenczy, A., Villa, L. L. and Franco, E. L. (2001). Persistent Human Papillomavirus Infection as a Predictor of Cervical Intraepithelial Neoplasia. Journal of American Medical Association. 286(24):3106-14.

Sellors, J. W. , Karwalajtys, T. L., Kaczorowski, J., Mahony, J. B., Lytwyn, A., Chong, S., Sparrow, J. and Lorincz, A; Survey of HPV in Ontario Women Group. (2003). Incidence, clearance and predictors of human papillomavirus infection in women. Canadian medical association journal.18:(4):421-5.

Serwadda, D., Wawer, M.J., Shah, K.V., Sewankambo, N.K., Daniel, R., Li, C., Lorincz, A., Meehan, M.P., WabwireMangen, F. and Gray, R.H. (1999). Use of a Hybrid Capture Assay of Self-Collected Vaginal Swabs in rural Uganda for detection of Human Papillomavirus. Journal Infectious Disease, 354:2545-2634.

Simen-Kapeu, K., Yhiskoshi, M., Syrjaneu, S., Diller, J. and Koskela, P. (2008). Smoking Impairs Human Papillous Virus (HPV) Type 16 and 18 Capsids Antibody Response following Natural HPV Infection. Scandinavian Journal of Infectious Diseases, 40(9): 745-751.
Sycuro, L.K., Xi, L.F., Hughes, J.P., Feng, Q., Winner, R.L., Lee, S.K., O'Reilly, S., Kiviat, N.B. and Koutsky, L.A. (2008). Persistence of Genital Human Papillomavirus Infection in a Long-term Follow-up Study of Female University Students. Journal of Infectious Diseases, 198: 971-978.

Tabora, N., Zelaya, A., Bakkers, J., Melchers, W. J. and Ferrera, A. (2005). Chlamydia Trachomatis and Genital Human Papillomavirus Infections in Female University Students in Honduras. American Journal of Tropical Medicine Hygiene. 73:50-53.

Thomas, M., Narayan, N., Pim, D., Tomaić, V., Massimi, P., Nagasaka, K., Kranjec, C., Gammoh, N. and Banks, L.(2008). Human Papillomaviruses, Cervical Cancer and Cell Polarity. Oncogene. 27(55):7018-30

Thomas, J.O., Herrero, R., Omigbodun, A.A., Ojemakinde, K., Ajayi, I.O., Fawole, A., Oladepo, O., Smith, J.S., Arslan, A., Munoz, N., Snijders, P.J.,Meijer, C.J and Franceschi,S. (2004). Prevalence Of Papillomavirus Infection In Women In Ibadan, Nigeria: A population-Based Study. British Journal of Cancer, 90: 638 -645.

Touzé, A., de Sanjosé, S., Coursaget, P., Almirall, M.R., Palacio, V., Meijer, C.J., Kornegay, J., Bosch F.X. (2001). Prevalence of anti-human papillomavirus types 16, 18, 31, and 58 virus-like particles in women in the general population and in prostitutes. Journal of Clinical Microbiology, 39: 4344-4348.

Trim, K. Nagji, N., Elit, L. and Roy, K. (2012). Parental Knowledge, Attitudes and Behaviours towards Human Papillomavirus Vaccination for Their Children: a systematic review from 2001 to 2011. Obstetician Gynecology International, 92(12): 36.

Vanchiere, J. and Demmer, G. (2004) Human polyomaviruses and papillomaviruses. In: Feigin Cherry, R. J., Demmler, G., and Kaplan, S., (eds). Textbook of Pediatric Infectious Diseases. 5th ed. Philadelphia: Saunders; 1809-1831

Watson, M., Saraiya, M. and Wu, X. (2009). Update of HPVassociated Female Genital Cancers in the United States, 19992004. Journal of Women Health, 18: 1731-1738.

WHO/ICO. (2012). Information Centre on HPV and Cervical Cancer (HPV Information Centre). Human Papillomavirus and Related Cancers in Nigeria. Accessed 25 ${ }^{\text {th }}$ October 2015.

Winkelstein, W. J. R., Edward, J. and Shillitoe R. B. K.J. (1984). Further Comment on Cancer of the Uterine Cervix, Smoking, and Herpesvirus Infections. American Journal of Epidemiology, 119:1

Wiredu, E. K. and Armah, H. B.(2006). Cancer Mortality Patterns in Ghana: A 10-Year Review of Autopsies and Hospital Mortality. Public Health. (6):159.

Zizipho Z. A. Mbulawa, Dianne J. Marais, Leigh F. Johnson, David Coetzee, and Anna-Lise Williamson (2012). Impact of Human Immunodeficiency Virus on the Natural History of 
Human Papillomavirus Genital Infection in South African (206):15-27.

Men and Women. The Journal of Infectious Diseases. 


\section{APPENDIX I}

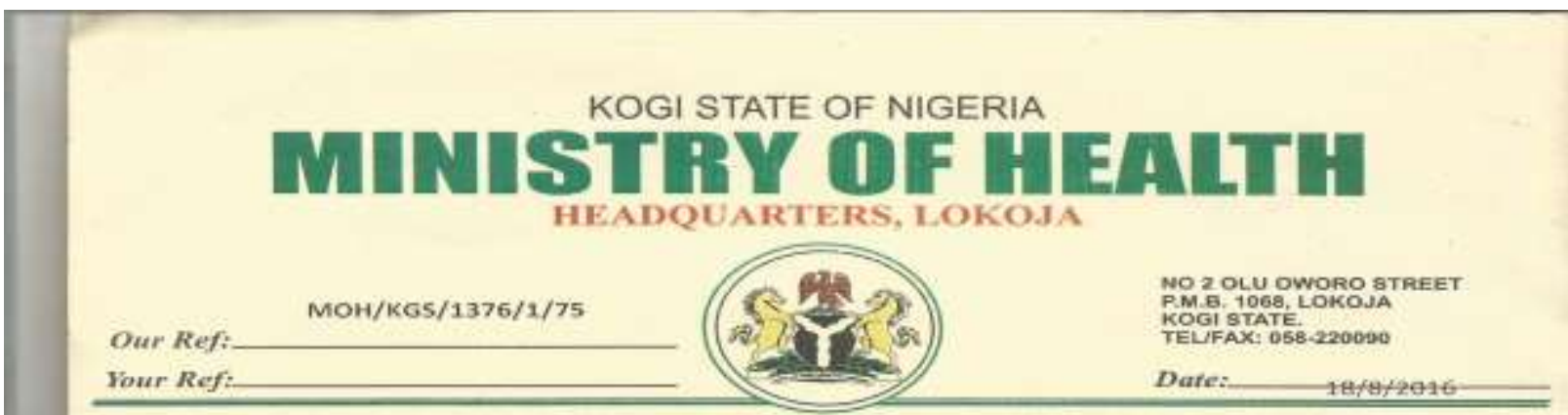

\section{ETHICAL CLEARANCE CERTIFICATE}

This is to certify that the Methodology being adopted

By

Awulu 0. Friday (p13scicios.2)

For the study of

Sero-Prevalence and PCR detection of Human Papilloma Viruses among Patients attending some Hospitals in Kogi East of Kogi State, Nigeria.

will not in any way impinge on the Ethical Standard of Medical Practice in Kogi State, Nigeria.

$$
\text { Dr. Isah } 8 .
$$

Secretary, Health Research Ethics Committee 